\title{
Equalorial
}

\section{Quilombolas de Acauã: Identidades, relações étnico-raciais e demarcação no Rio Grande do Norte, Brasil.}

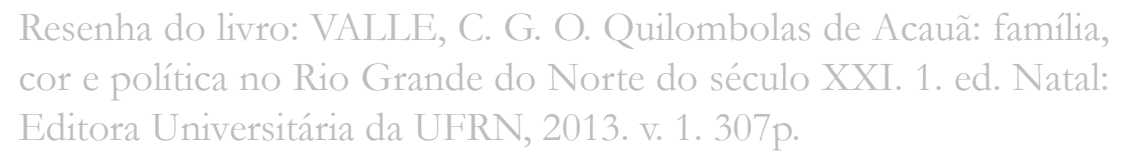

Editora Universitária da UFRN, 2013. v. 1. 307p.

Antônio Ricardo Ximenes de Araujo

Mestrando em Antropologia Social

Universidade Federal do Rio Grande do Norte ricardox@ufrn.edu.br

Carlos Guilherme Octaviano do Valle, o autor, é mestre em Antropologia Social pelo Programa de Pós-Graduação em Antropologia Social/PPGASMuseu Nacional, da Universidade Federal do Rio de Janeiro/UFRJ (1993) e realizou o doutorado no Departamento de Antropologia do University College London, Grã-Bretanha (2000). Seus interesses de pesquisa transitam por diversas áreas, tais como: Antropologia do Corpo, da Saúde e Doença; Antropologia das Emoções e das Subjetividades, Sexualidades e Identidades; Etnicidade e etnologia Indígena no Nordeste brasileiro; dentre outras. Atualmente é Professor Associado IV no Departamento de Antropologia da UFRN e é neste contexto que escreve Quilombolas de Acanã: família, cor e política no Rio Grande do Norte do século XXI.

A referida obra se destaca, principalmente, por ser fruto de um estudo voltado para a construção de um laudo antropológico da comunidade de Acauã, localizada na cidade de Poço Branco-RN, finalizado em dezembro de 2006, fru- 
to de um convênio entre o INCRA/Ministério do Desenvolvimento Agrário, o Departamento de Antropologia da Universidade Federal do Rio Grande do Norte (DAN/UFRN) e a Fundação Norte-Rio-Grandense de Pesquisa e Cultura (FUNPEC). Devemos, portanto, contextualizar a obra no conjunto de outros estudos desenvolvidos pelos pesquisadores do DAN neste mesmo convênio.

Por ser baseado em um laudo antropológico, o livro passou por uma reformulação e adequação em sua forma e conteúdo visando facilitar sua capilaridade e circulação. Se antes era apresentado em duas partes que dividiam os conteúdos entre "fundamentos teóricos" e "estudo etnográfico", nesta versão o título da parte I é suprimido pelo autor, com o intuito de explicitar as imbricações entre "teoria" e "campo". Esta perspectiva será desenvolvida ao longo do texto, principalmente, no tratamento dos dados etnográficos utilizados para a construção de argumentos que sustentem as perspectivas do autor.

O primeiro capítulo, intitulado "Raça, cultura e etnicidade", tem por objetivo fomentar uma discussão de cunho teórico-metodológico sobre os aportes conceituais que vão direcionar a forma como o trabalho será desenvolvido. Quando o autor chama a atenção para a importância da "contextualização histórica" neste tipo de trabalho, são tecidas críticas aos processos históricos de "racialização do ocidente", bem como a construção sociopolítica da "mestiçagem” no Brasil. Partindo de uma discussão sobre a operacionalização cultural e simbólica destes conceitos, são tensionadas as categorias que historicamente serviram para construção das hierarquias biologizantes. O autor propõe a utilização de conceitos relacionados aos processos de diferenciação étnica para que possamos entender a forma como são estabelecidas as fronteiras e contrastes entre grupos etnicamente diferenciados, tendo por objetivo a superação das noções de "aculturação", "assimilação" e "integração". (p. 55)

A obra de Câmara Cascudo, um dos principais historiadores do RN, é uma referência indispensável para entendermos os processos sócio-históricos específicos deste estado. Seja pela organização historiográfica por ele produzida ou pelos impactos de sua obra na construção de verdades históricas sobre a presença de populações negras. No entanto, algumas ressalvas e críticas são necessárias para a utilização do material produzido por Cascudo, Valle nos direciona para situações que condicionam as limitações teóricas que esse deslocamento 
pode causar. Inspirado em Gilberto Freyre, Cascudo narra a forma como as "três fontes étnicas" construíram a nação brasileira a partir do contexto específico do RN. Por mais que as "ambiguidades nas formas de apresentação da presença e influência negra” sejam passíveis de críticas, é inegável a necessidade de nos debruçarmos sobre esse autor para entendermos os contextos locais em que estão inseridas essas populações. Muitas vezes percebidos, nos termos "culturalistas", como elementos residuais de culturas perdidas, estas relações étnico-sociais devem ser compreendidas considerando a dinâmica dos processos de estigmatização e as estratégias étnicas.

Este é o ponto de partida para o segundo capítulo, "Variações Históricas", no qual serão discutidas as transformações e configurações econômicas, políticas e historiográficas que desenharam as redes de relações da região em que está estabelecida a comunidade de Acauã. Chamam a atenção, nesta análise histórica proposta pelo autor, os deslocamentos discursivos realizados pelos historiadores modernos que, mesmo mantendo determinados vícios de observação, tendem a fazer uma releitura dos processos que configuraram o Nordeste brasileiro. São feitas ressalvas no que diz respeito às populações que compuseram o cenário colonial, com especial atenção aos povos indígenas, que se estabeleceram no estado ao longo dos séculos de "guerras", extermínios e esbulho de terras, gerando deslocamentos "estratégicos", expulsões, bem típicas das relações históricas consideradas. Este processo tem como plano de fundo as dinâmicas econômicas locais e internacionais, com enfoque principalmente nas produções de cana-de-açúcar, algodão e gado.

Estes recortes nos são interessantes para compreendermos os processos de escravidão negra do Rio Grande do Norte, especificamente no vale do Rio Ceará-Mirim. As limitações interpretativas dessas histórias marcadas pelo espólio colonial das produções materiais, são contextualizadas em documentos históricos e produções de historiadores que se debruçaram sobre essas narrativas. O autor sugere, então, que esta contextualização é deveras importante tanto em termos de releitura da história oficial, como na compreensão das forças políticas que condicionaram as populações locais. Os grandes empreendimentos coloniais e republicanos, administrados pelos interesses das elites dominantes, são peças-chave nestes processos de diferenciação étnicas e impactaram as constru- 
ções culturais desta região.

Como já citado, o próprio estudo etnográfico desenvolvido pelo autor fundamenta a construção textual da segunda parte, na qual a noção de etnografia abordada é importantíssima para a avaliação dos rumos que a obra toma a partir daqui. Em termos teórico-metodológicos, é indispensável percebermos os aportes discursivos sobre os quais este tipo de produção intelectual está fundamentada, ressaltando que este é um dos pilares fundadores do próprio fazer antropológico. Mesmo que seja proposta uma linguagem diferenciada, tendo em vistas a especificidade de forma e conteúdo exigida pelos "laudos antropológicos", o diálogo com outros pensadores em antropologia se torna fundamental.

É interessante notarmos que as produções etnográficas são, como sugerido pelos autores pós-modernos da disciplina, também produções textuais que nos exigem meticuloso cuidado epistemológico. $\mathrm{O}$ autor começa, então, a desenhar o seu estudo etnográfico onde serão abordados os dados qualitativos da comunidade de Acauã e das suas relações com comunidades próximas, "a cidade de Poço Branco e o povoado de Contador”, especialmente. Assim sendo, nos capítulos seguintes serão abordados os aspectos "demográficos, genealógicos, políticos, históricos, econômicos e culturais” (p. 113).

No capítulo 3, "População, organização sociopolítica e parentesco", o autor busca conhecer as formas de organização da comunidade, bem como a disposição dos sujeitos nas relações políticas. Composta por uma população de 224 pessoas, distribuída em 56 unidades familiares, que estão ligadas por laços de parentesco e casamento, a comunidade possui formas de organização bem comuns a outras populações rurais do nordeste brasileiro. No entanto, algumas ressalvas são necessárias, especialmente sobre a maneira como a rede de famílias e alianças se desenrola nesta localidade, possuindo características bem específicas de grupos etnicamente diferenciados, tais como a busca por uma continuidade social das formas de organização e distribuição dos bens materiais e culturais.

As relações de gênero existentes entre estes sujeitos são também abordadas pelo autor nas figurações produzidas. Segundo ele, é comum que mulheres se ocupem com mais empenho dos cuidados com as unidades domésticas e 
os processos de saúde e doença. De forma não essencialista, ele faz uma ressalva quanto a rigidez destes modelos que nem sempre são desempenhados por todos os sujeitos. A segurança e continuidade dos corpos é tida como uma demanda explicitamente feminina, assim como as atividades relacionadas aos recursos hídricos, tão fundamentais à vida destas pessoas. Entender a forma como estão distribuídas atividades cotidianas, levando em conta as relações de gênero, é fundamental para a análise proposta pelo autor, pois é a partir destes aspectos que serão formuladas as práticas de reprodução e continuidade social da comunidade.

Outras formas de aliança, para além do casamento católico, "de vela", são tidas como formas paralelas e complementares de se estabelecer laços de comunidade e compartilhamento dos destinos. As relações compadrio e apadrinhamento, por exemplo, são exploradas tanto em termos religiosos como em termos de "cultura popular". É comum para estas pessoas a ritualização do batismo de "fogueira", que destinará os participantes ao estabelecimento de relações e formas de tratamento bem específicas. Estes eventos refletem práticas rituais muito difundidas em outras comunidades rurais no nordeste brasileiro, com o adendo de que as significações produzidas sobre elas variam de localidade para localidade. Assim, os elementos acionados discursivamente para explicar emicamente as alianças produzidas, tendem a hierarquizar as ritualísticas.

Tais formas de acesso a explicações das relações na comunidade serão amplamente abordadas no capítulo 4, "Cultura, memória e etnicidade: tempos da Cunhã Velha e de Acauã”, no qual, como o título sugere, serão discutidas as narratividades formuladas pelos processos de memoração. São abordadas as múltiplas interpretações do passado e as formas como os processos de diferenciações, entre os "de dentro" e os "de fora" figuram na memória social destas pessoas e constroem as suas noções semânticas da etnicidade. É dada uma certa importância à própria "imprecisão" que caracteriza as reconstruções de um passado não objetificado. O que importa aqui são os processos de legitimidade discursiva, sobre as memórias internas, que orientam as narrativas sobre a origem da comunidade.

São comuns os relatos sobre os processos de "fuga" da escravidão e "negros escondidos" dos antigos senhores. Tais figurações operam como ideias 
basilares ao diferenciamento social ancorado na cor da pele e nas noções que se desenvolveram sobre a raça. Estes marcadores, segundo o autor, também são acionados de maneira ambígua pelas pessoas da comunidade quando falam de suas relações com os de fora que, ora constroem uma visão benevolente dos negros de Acauã, ora operam noções preconceituosas e estigmatizantes sobre os moradores. Este capítulo nos serve para que tenhamos uma noção das interações simbólicas que operam as categorias etnicamente diferenciadas. Essa discussão é compreendida como indispensável para compreendermos as dimensões que marcam a relação destes sujeitos com a localidade em que vivem, bem como as fronteiras estabelecidas nos processos de reivindicação do território.

Tais temáticas serão encadeadas no capítulo 5, "História, territorialidade e territorialização", no qual serão discutidas as conexões históricas entre as construções étnicas e as "visões intrínsecas de territorialidade". Nesta parte da obra, o autor tenta esboçar as relações que a forma como as representações de origem da comunidade são elaboradas, passando por uma compreensão do espaço territorializado para além da sua utilidade material e econômica. São discutidas as categorias nativas de terra apossada e terra aforada, com o intuito de entender o sentido que as comunidades tradicionais, como Acauã, empregam ao seu pertencimento étnico. Ao rememorar os processos históricos que levaram aquele povo a sua configuração atual são flexionadas as ideias de "velho" e "novo" com as quais eles constroem suas narrativas. Um evento central, a construção da barragem de poço Branco em 1960, é acionado para descrever a forma como foram deslocados de um lugar de origem e obrigados a entrar na "luta" pelo direito a uma vida digna.

As concepções de terras do Estado e datas de Dom Pedro são frequentemente acionadas para referir-se ao território sobre o qual pretendem construir suas vidas. Estas relações espaciais do território representam para estes sujeitos a possibilidade de manutenção, principalmente, das relações culturais e simbólicas que lhes são características. É importante ressaltar a forma como o autor elabora metodologicamente sua compreensão das territorializações, o uso de croquis elaborados pelos interlocutores serve de ponto de partida para discutir os deslocamentos ocasionados pela construção da barragem. Como exemplo dos prejuízos causados pela forma como foram retirados de seu antigo local, 
percebemos a dificuldade de acesso aos recursos hídricos, que provocou o abandono das produções de cerâmicas e das práticas de olaria. É rapidamente citado também, o alagamento do antigo cemitério, onde os moradores de Cunhã velha depositavam os seus mortos. Estes aspectos se tornam ainda mais violentos quando relatadas as negociações em torno da indenização proposta, onde só foram consideradas as casas construídas.

Ao passo que nos aproximamos da conclusão da obra, as discussões contidas no capítulo 6, "Terra de trabalho, terra arrendada: organização e sustentabilidade econômica", configuram uma síntese das relações desenvolvidas por estes sujeitos, chamando a atenção para esferas da vida indispensáveis ao sustento de uma comunidade tradicional. De notada vocação agrícola, a comunidade desenvolve, quando possível, a prática de roçados, na maioria das vezes em terras arrendadas. O desenvolvimento de um pequeno comércio local é ressaltado pelo autor como reflexo de trajetórias individuais muito relacionadas aos "padrões de escolaridade" e à "participação política". A maioria das famílias recebe algum tipo de "benefício estatal" que lhes serve como complemento da renda familiar. São descritos também neste capítulo os quintais e a relação com as árvores frutíferas da região.

O ponto forte deste capítulo é, sem dúvidas, a relação que os sujeitos desenvolvem com a terra, principalmente, nas situações em que eles têm de arrendar terras vizinhas para o plantio e como isso impacta suas produções econômicas. A falta de terras cultiváveis é um dos fatores que interpõe dificuldades no sustento de suas vidas, colocando os trabalhos sazonais em outras localidades como principal estratégia de sobrevivência. Assim, a elaboração demonstra que somente através dos processos demarcatórios, a comunidade poderá construir sua plena autonomia econômica familiar, uma vez que tais dificuldades de acesso à terra e aos recursos hídricos constituem um dos principais problemas da comunidade.

Findado o último capítulo do livro, o autor parte para sua conclusão, que dá conta do "Parecer antropológico sobre a comunidade Quilombola de Acauã com proposta de delimitação". Aqui é expresso um breve resumo de tudo que foi abordado e discutido ao longo do laudo com o intuito de estabelecer de forma lúcida o posicionamento de antropólogo. Para ele, a comunidade dispõe 
de todos os elementos que tornam possível sua conceituação como "terra ocupada por remanescente das comunidades de quilombos", conceito elaborado pelo INCRA. O relatório recomenda, então, que sejam feitas as demarcações necessárias e conferido o título definitivo de posse das áreas pleiteadas pela comunidade, visando a sua continuidade histórica e prevendo o seu crescimento populacional.

O livro ainda nos traz uma última sessão, escrita posteriormente à entrega do laudo, na qual são discutidos os desdobramentos da pesquisa realizada. São narrados os acirramentos e conflitos causados pela insatisfação de alguns proprietários de terras na região, a quem não interessava esta demarcação. As contestações jurídicas tomam uma importância destacada nesta sessão por possibilitarem uma reflexão sobre a própria práxis etnográfica e a sua legitimidade enquanto saber técnico-científico. Encerra-se o livro com a relevante informação de que em abril de 2013 a comunidade de Acauã conseguiu a titulação definitiva de parte de suas terras.

A obra em questão nos abre a possibilidade de algumas discussões antropológicas de acentuada relevância. Podemos percebê-la, então, como uma construção discursiva que possui certas especificidades. Em primeiro lugar, nos chama a atenção, a forma como são distribuídas e acessadas as hierarquias entre os saberes. O antropólogo na construção do seu texto deve elaborar estratégias para um diálogo possível tanto com os saberes jurídico/estatais, os quais demandam seu parecer, quanto com a comunidade com a qual está escrevendo o texto. Torna-se necessário assim, o posicionamento como mediador de forças frequentemente mencionadas. As estratégias textuais ou fições persuasivas (STRATHERN, 2013) são importantíssimas para que se encontre o "tom" da obra a ser produzida.

Em segundo lugar, gostaríamos de atentar especialmente às discussões sobre as identidades étnicas e os processos de territorialização. Tais conceituações devem operar um espaço de inter-relações políticas, posto que os objetos aos quais elas se referem são na maioria dos casos demandados por populações historicamente marginalizadas (LIT'TLE, 2002). Neste sentido, é indispensável que o discurso antropológico tenha a maleabilidade necessária para acessar as esferas tecnicistas, do conhecimento científico, sem abrir mão das elaborações 
políticas dos "sujeitos reais". Não deve o antropólogo se considerar o "branco salvador", mas ter em seus princípios ético-profissionais um direcionamento que torne possível retribuir, na justeza de suas produções, os conhecimentos oferecidos pelos seus interlocutores.

\section{Referências}

STRATHERN, Marilyn. Fora de contexto: as ficções persuasivas da antropologia. São Paulo: Terceiro Nome, 2013.

LITTLE, Paul F. 2002. Territórios sociais e povos tradicionais no Brasil: por uma antropologia da territorialidade. Série Antropologia, $\mathrm{n}^{\circ} 32$. Brasília.

Recebido em 01 de dezembro de 2018 Aceito em 11 de maio de 2019 